\title{
Spotlight on measles 2010: Update on the ongoing measles outbreak in France, 2008-2010
}

I Parent du Châtelet (i.parent@invs.sante.fr) ${ }^{1}$, D Antona ${ }^{1}$, F Freymuth ${ }^{2}$, M Muscat ${ }^{3}$, F Halftermeyer-Zhou ${ }^{1}$, C Maine ${ }^{1}$, D Floret ${ }^{4}$,

D Lévy-Bruhl ${ }^{1}$

1. Institut de Veille Sanitaire (InVS, French Institute for Public Health Surveillance), Saint-Maurice, France

2. National Reference Centre for Measles, Caen, France

3. EUVAC.NET hub, Department of Epidemiology, Statens Serum Institut, Copenhagen, Denmark

4. Claude Bernard Lyon 1 University, French working group on measles and congenital rubella elimination, Lyon, France

Citation style for this article:

Parent du Châtelet I, Antona D, Freymuth F, Muscat M, Halftermeyer-Zhou F, Maine C, Floret D, Lévy-Bruhl D. Spotlight on measles 2010: Update on the ongoing measles outbreak in France, 2008-2010. Euro Surveill. 2010;15(36):pii=19656. Available online: http://www.eurosurveillance.org/ViewArticle. aspx?Articleld $=19656$

Article published on 9 September 2010

Since early 2008 , France has been experiencing a measles outbreak with almost 5,000 notified cases as of 30 June 2010, including three measles-related deaths. The proportion of cases 20 years or older reached $38 \%$ during the first half of 2010 . This situation is the consequence of insufficient vaccine coverage $(90 \%$ at age 24 months in 2007) that led to the accumulation of susceptibles over the last years. It underlines the need for additional measures targeting susceptible children and young adults.

The current measles outbreak in France was first noticed in early 2008 [1] when a preliminary number of 579 notified measles cases contrasted sharply with the low number of notified cases in 2006 and 2007 (44 and 40 cases, respectively). The outbreak intensified and continued to spread throughout the country during 2009 and 2010 with a total number of notified cases that has reached almost 5,000 by 30 June 2010 .

In France, a combined measles-mumps-rubella (MMR) vaccine has been recommended since 1986 . The first dose is currently recommended at the age of 12 months and the second dose during the second year of life. A catch-up measles vaccination programme with two doses is recommended for children born in 1992 or later. For those born between 1980 and 1991, a single MMR vaccine dose is recommended [2].

Measles has been a mandatory notifiable disease in France since mid-2005. Clinicians and microbiologists are requested to report suspected measles cases immediately to the regional public health authorities. Notifications are collected and analysed at national level by the French Institute for Public Health Surveillance (InVS).

We included in our analysis the notified clinical and confirmed cases with a date of rash onset between January 2008 and June 2010 (preliminary data). A confirmed case can be i) laboratory-confirmed, by detecting either measles IgM antibodies or measles virus nucleic acid using RT-PCR in serum or oral fluid, or ii) epidemiologically confirmed, when a link with a laboratory-confirmed case is proven. Case definitions for measles are detailed on the InVS website [3].

\section{Outbreak description}

The outbreak started during early spring 2008 among students attending traditionalist catholic private schools for whom a low immunisation coverage was identified retrospectively [1]. It then spread first into other schools including public ones, and by the end of 2008 into the general population. The outbreak also affected socially vulnerable communities such as France's nomadic minorities ('gens du voyage') and Roma communities.

A total of 4,753 cases were notified as of 30 June 2010: 604 cases in 2008, 1,544 in 2009 and 2,605 in the first half of 2010 (Figure 1).

After excluding 99 cases ( $2 \%$ ) who had returned from abroad within 7-18 days before the rash onset, the incidence of indigenous measles was highest, four cases per 100,000 population, in the first half of 2010, compared with 2.3 in 2009 and 0.9 in 2008 (p<0.0001). In 2010 , the crude incidence was higher than 5.0 per 100,000 population in seven of the 22 regions in mainland France (Figure 2). Only three cases were reported from the French overseas regions but for two of these cases, the transmission has most likely occurred in mainland France.

The proportion of laboratory-confirmed cases increased from $50 \%(n=306)$ in 2008 , to $54 \%(n=832)$ in 2009 and to $56 \%(n=1,410)$ in the first half of 2010 .

The National Reference Centre for Measles in France identified the main measles virus genotypes in 2009 as D4 and D5. They accounted for $75 \%$ and $20 \%$ respectively of 284 genotyped cases. Genotypes D8, $\mathrm{H}_{2}$ and $\mathrm{B}_{3}$ accounted for the remaining $5 \%$. Genotype D4 became predominant in 2010 (99\% of the 467 
genotyped cases). A great majority of the strains are linked to the last D4 variant identified in the United Kingdom in 2007, MVs/Enfield.GBR/14/07 (Genebank accession number EF600554).

Among the 4,753 cases, the sex ratio $M / F$ was equal to 1.08. In 2010, the age distribution of measles cases has changed significantly compared with 2009 and 2008. The proportion of cases under one year of age has increased significantly from $4 \%(n=25)$ in 2008 to $8 \%(n=126)$ in 2009 (p<o.001) and $9 \%(n=243)$ in 2010 ( $p<0.001$ ). The proportion of cases aged 20 years or older increased from $17 \%(n=100)$ in 2008 to $23 \%$ $(n=360)$ in $2009(p=0.002)$ and $38 \%(n=992)$ in 2010 ( $p<0.001)$. In the first half of 2010, the highest agespecific incidence rate was found in children under the age of two years (Figure 3). Over this six-month period, $56 \%(n=135)$ of the cases under one year of age were younger than nine months.

In $2010,82 \%$ of the 2,123 cases with a known vaccination status were unvaccinated, $13 \%$ had received one dose, $3 \%$ two doses and $2 \%$ had been vaccinated with an unspecified number of doses. A high proportion of unvaccinated cases (86\%) was observed among the cases aged between 5 and 19 years, who should have been vaccinated with two MMR doses. The highest proportion of cases vaccinated with at least one dose of MMR was 32\% (156/487) in 20-29-year-old adults (Figure 4).

\section{FIGURE 1}

Notified measles cases by month of rash onset, France, January 2008 - June $2010(n=4,753)$

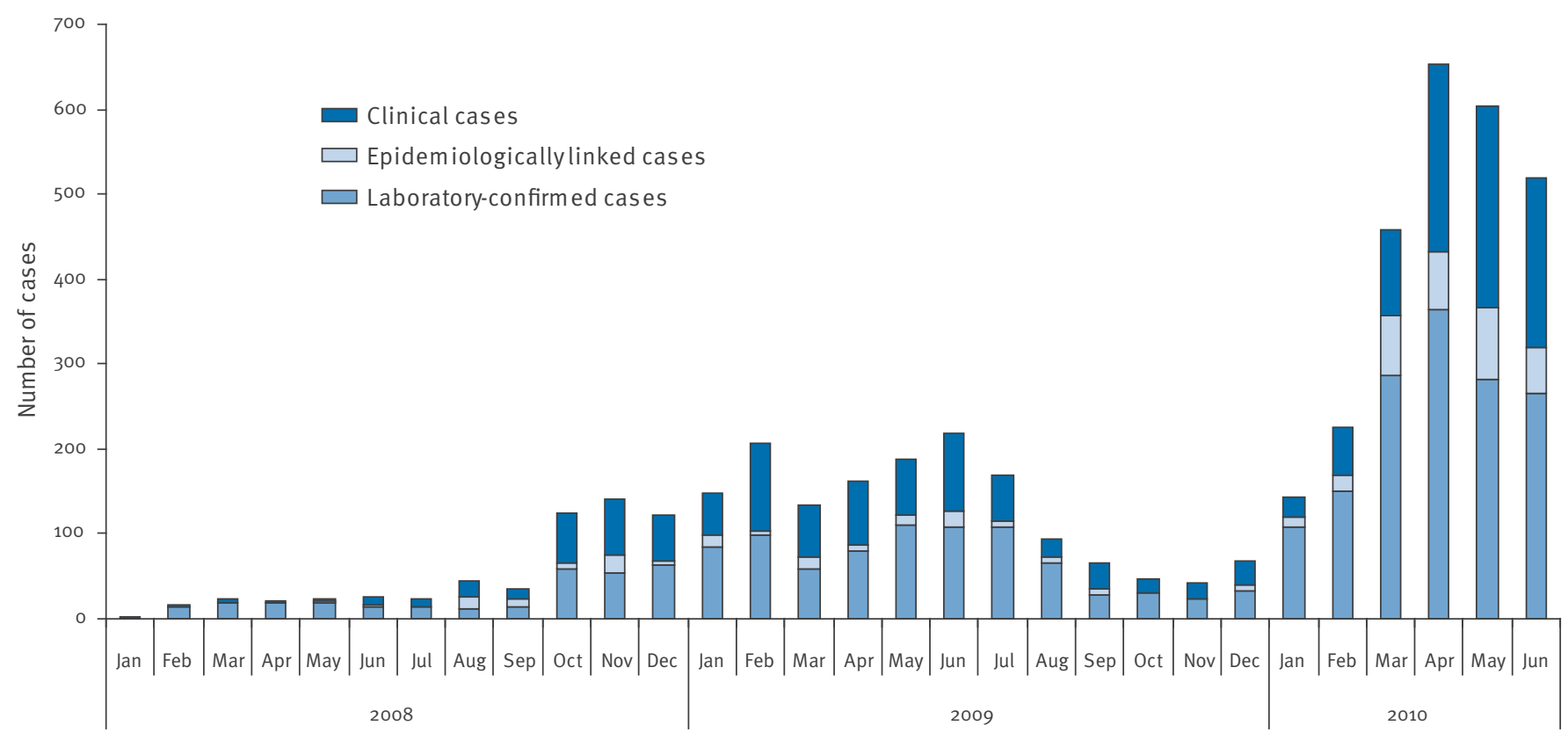

\section{FIGURE 2}

Incidence of notified measles cases, by regions, France, January 2008 - June 2010
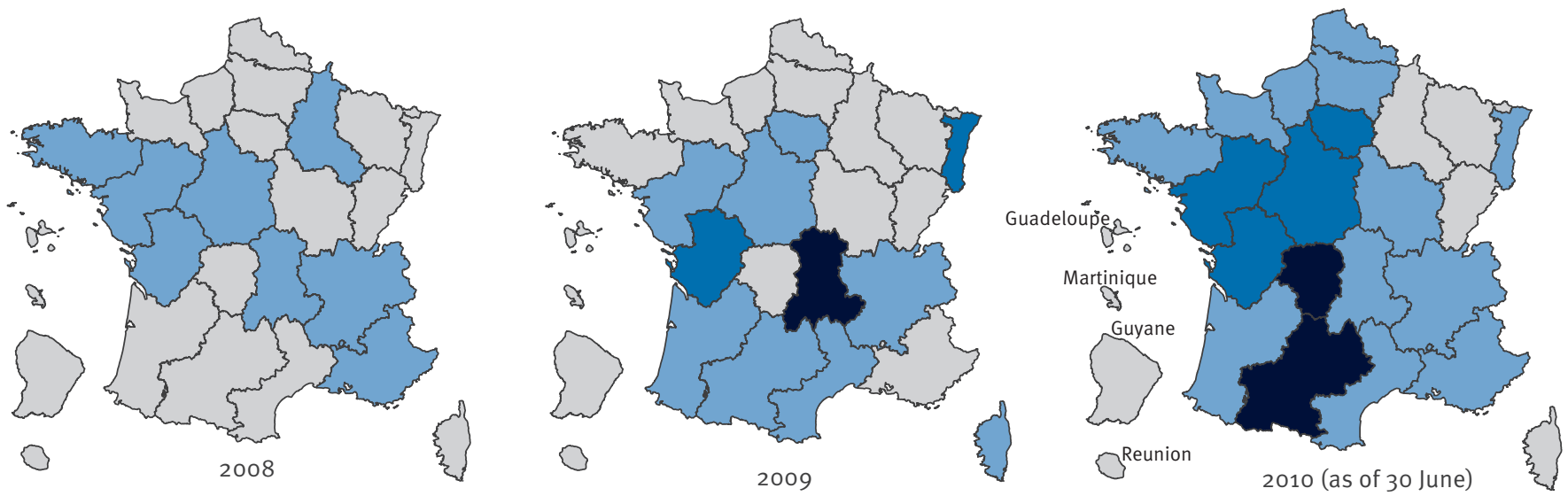

Incidence rate (per 100,000 population) 


\section{Complications and deaths}

Throughout the study period, $35 \%(n=137)$ of the cases under the age of one year, $18 \%(n=549)$ of the cases in the age group of 1 -19-year-olds and $50 \%(n=725)$ of the cases aged 20 years or older were hospitalised. The percentage of hospitalised cases increased from $18 \%(n=110)$ in 2008 to $27 \%(n=422)$ in 2009 and to $34 \%(n=879)$ in 2010 (p<0.0001) reflecting the change

\section{FIGURE 3}

Age-specific incidence rates of measles cases, France, January 2008 - June 2010

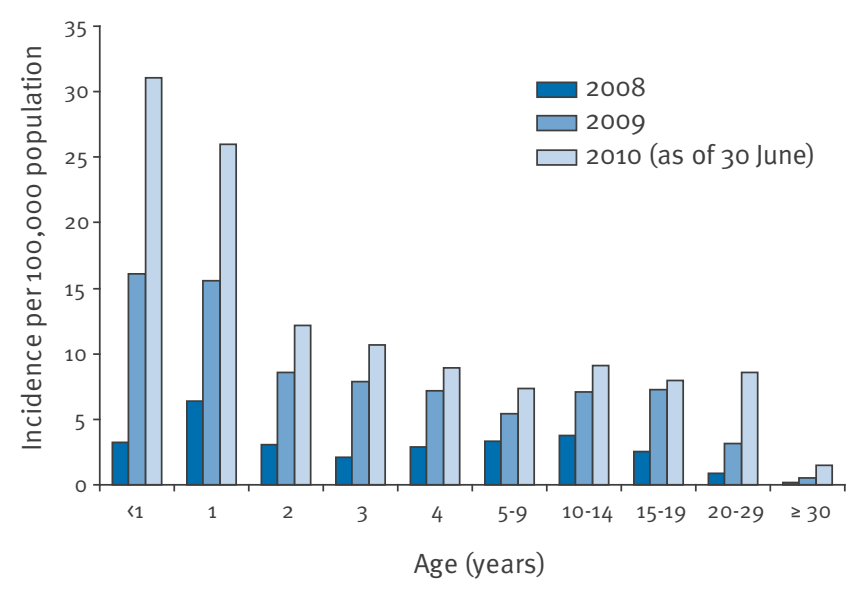

\section{FIGURE 4}

Vaccination status of measles cases by age groups, France, January-June $2010(n=2,123)$

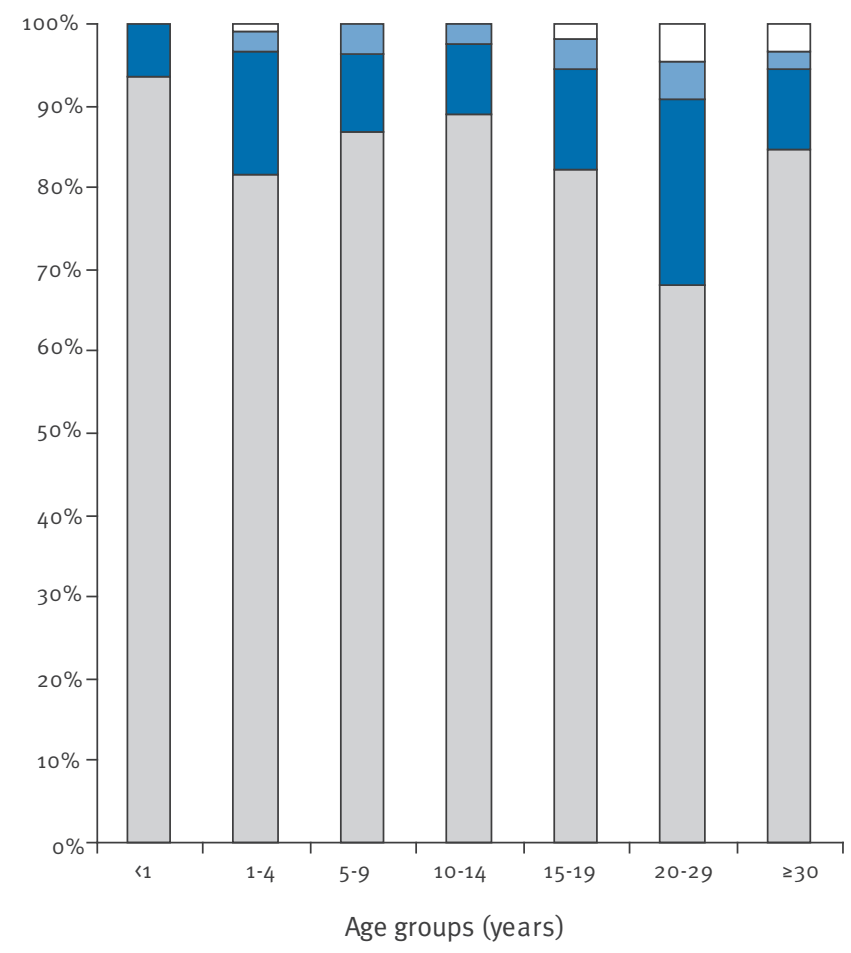

$\square$ Vaccinated with unknown number of doses of MMR

$\square$ Vaccinated with two doses of MMR

Vaccinated with one dose of MMR

$\square$ Unvaccinated in age distribution. In fact, the proportion of complications reported for the hospitalised cases was significantly higher among the cases aged 30 years or older $(40 \%)$ than in the younger age groups $(25 \%, p<0,001)$, whereas it remained stable over time $(25 \%, 26 \%$ and $29 \%$ in 2008, 2009 and 2010 respectively). Among the hospitalised cases, three cases of acute measles encephalitis and 253 cases of measles-related pneumonia were reported.

Three measles-related deaths occurred during the study period: two in 2009 and one in 2010, all among unvaccinated cases. One death was linked to acute encephalitis in a 12-year-old girl and the other two occurred in young men, aged 23 and 18 years, with underlying immunodeficiency disorders (Crohn and Hodgkin).

\section{Control measures}

Specific control measures including catch-up and postexposure vaccinations were recommended by local health authorities, targeting affected populations according to national guidelines within the National Plan for Elimination of Measles [4]. In case of localised outbreaks or clusters, the catch-up recommendation is to reach two doses of MMR vaccine for the susceptible individuals (not vaccinated or without history of measles) aged between 12 months and 45 years in the affected area or community.

Communication to the general public (e.g. leaflets, newspapers) and health professionals (e.g. medical journals) has been strengthened with also specific emphasis to the religious community concerned and to the national 'gens du voyage' associations (a meeting between representatives from the Ministry of Health and from the affected groups). Advantage was taken of the European Immunisation Weeks (EIW) in April 2009 and 2010 to reinforce this communication, with a special focus on the vaccination recommendations [5].

\section{Discussion}

Our data show that France has emerged as another among several European countries (e.g. Bulgaria, Switzerland, Ireland) with more than one measles case per 100,000 population (i.e. having a high incidence according to the criteria set by the World Health Organization (WHO) for the elimination of measles), together with countries like Greece, and Germany which have recently experienced measles outbreaks [6-11].

Measles reporting rate has probably increased since early 2008 in France. However, several factors still argue for an underestimation of the current incidence of the disease. The high proportion of hospitalised cases probably reflects a higher compliance of hospital health professionals than of general practitioners with regard to the notification of measles cases. In some local outbreak investigations less than $50 \%$ of cases were notified, and once a case was diagnosed in a household, the secondary cases were less likely 
to seek medical advice. The number of patients with measles-positive results in the data collected from the main laboratories testing for measles IgM in France was 1.5 higher than the number of positive cases that were notified. The spread of the disease among socially vulnerable communities is even more difficult to assess because the notification forms do not contain information on social conditions.

It had already been predicted in 1998 that countries like France or England and Wales, where vaccine coverage had remained around $80 \%$ to $85 \%$ for many years with insufficient catch-up programmes, have built up large cohorts of susceptible people, becoming prone to large outbreaks with an increase of the average age of cases [12] .

Despite the current French recommendations, immunisation coverage for measles remains insufficient. At the age of two years, the vaccination coverage with one dose of MMR vaccine was estimated at 90\% in 2007 . Information on vaccination coverage in France is to be found on InVS website [3].

The vaccination coverage survey conducted in the school year 2005-6 among six-year-old school children, has shown a vaccination coverage of $93 \%$ for the first dose of an MMR containing vaccine and $44 \%$ for the second dose, and the one conducted in 2004-5 among 11 -year-olds has shown a vaccination coverage of $96 \%$ and $74 \%$ respectively [13] .

The proportions of vaccinated cases in different age groups have to be interpreted with caution. It is possible that cases being more severe in the age group of 20-29-year-olds are more likely to be hospitalised and notified. The proportion of vaccinated cases in this population born after MMR introduction could therefore reflect a more accurate picture of the virus circulation in a population with suboptimal vaccination coverage.

Both awareness of the disease and a commitment by the French health authorities and health professionals are essential to strengthen the vaccination programme. The current measles situation in France underlines the need for additional urgent measures, both in terms of communication and vaccination, targeting susceptible children and young adults.
4. French Ministry of Health and Sports. Circular No. DGS/ Rl1/2009/334 of 4 November 2009 on the mandatory notification of individual data to the health authority in case of measles and implementation of preventive measures around a case or a cluster. French. Available from: http://www.santesports.gouv.fr/IMG/pdf/o9 334topdf.pdf

5. French Ministry of Health and Sports/National Institute for Prevention and Health Education. [European Immunisation Week]. French. [Accessed 9 Sep 2010]. Available from: http:// inpes.com6-interactive.fr/semaine europeenne vaccination. html

6. Muscat M, Bang H, Wohlfahrt J, Glismann S, Mølbak K, EUVAC. NET group. Measles in Europe: an epidemiological assessment. Lancet. 2009;373(9661):383-9.

7. World Health Organization. Eliminating measles and rubella and prevention congenital rubella infection, WHO European Region strategic plan 2005-2010. [cited February 28, 2008] Available from: http://www.euro.who.int/document/E87772. pdf

8. Euvac.net. Measles surveillance annual report 2009. Available from http://www.euvac.net/graphics/euvac/pdf/annual_2009. pdf

9. Pervanidou D, Horefti E, Patrinos S, Lytras T, Triantafillou E, Mentis A, et al. Spotlight on measles 2010: Ongoing measles outbreak in Greece, January-July 2010. Euro Surveill. 2010;15(30):pii=19629. Available from: http://www. eurosurveillance.org/ViewArticle.aspx?Articleld=19629

10. Bätzing-Feigenbaum J, Pruckner U, Beyer A, Sinn G, Dinter A, Mankertz A, et al. Spotlight on measles 2010: Preliminary report of an ongoing measles outbreak in a subpopulation with low vaccination coverage in Berlin, Germany, JanuaryMarch 2010. Euro Surveill. 2010;15(13):pii=19527. Available from: http://www.eurosurveillance.org/ViewArticle. aspx?Articleld $=19527$

11. Marinova L, Kojouharova M, Mihneva Z. An ongoing measles outbreak in Bulgaria, 2009. Euro Surveill. 2009;14(26):pii=19259. Available from: http://www. eurosurveillance.org/ViewArticle.aspx?Articleld=19259

12. Lévy-Bruhl D, Pebody RG, Veldhuijzen I, Valenciano $M$, Osborne K. ESEN: a comparison of vaccination programmes - Part three : measles mumps and rubella. Euro Surveill. 1998;3(12):pii=112. Available from: http://www. eurosurveillance.org/ViewArticle.aspx?Articleld=112

13. Fonteneau L, Urcun IM, Kerneur C, Guthmann IP, Guignon, Lévy-Bruhl D, et al. Vaccination coverage of 11 years old junior school-children (5th grade), France, 2004-2005. Bull Epidémiol Hebd. 2008;51-52:493-7. French. Available from: http://www. invs.sante.fr/beh/2008/51_52/beh_51_52_2008.pdf

1. Parent du Châtelet I, Floret D, Antona D, Lévy-Bruhl D. Measles resurgence in France in 2008, a preliminary report. Euro Surveill. 2009;14(6):pii=19118. Available from: http://www. eurosurveillance.org/ViewArticle.aspx?Articleld=19118

2. Institut de Veille Sanitaire (InVS). 2010 vaccination schedule and recommendations from the "Haut conseil de la santé publique' in France. Bull Epidémiol Hebd;2010;14-15:121172. French. Available from: http://www.invs.sante.fr/ beh/2010/14_15/beh_14_15.pdf

3. Institut de Veille Sanitaire (InVS). [Measles]. InVS; [updated 13 Jan 2010]. French. Available from: http://www.invs.sante.fr/ surveillance/rougeole 